\title{
Lipoprotein-Proteoglycan Complexes Induce Continued Cholesteryl Ester Accumulation in Foam Cells from Rabbit Atherosclerotic Lesions
}

\author{
Parakat Vijayagopal, * * Sathanur R. Srinivasan, * " "| Ji-Hua Xu," Edward R. Dalferes, Jr.," \\ Bhandaru Radhakrishnamurthy," and Gerald S. Berenson" \\ Departments of * Medicine, ${ }^{\ddagger}$ Anatomy, and ${ }^{\S}$ Biochemistry, Louisiana State University Medical Center, New Orleans, Louisiana 70112 ; \\ and "Department of Applied Health Sciences, Tulane School of Public Health \& Tropical Medicine, New Orleans, Louisiana 70112
}

\begin{abstract}
We studied the metabolism of lipoprotein-proteoglycan complexes by macrophage-derived foam cells. Foam cells were isolated from atherosclerotic rabbit aortas. ApoB-lipoproteinproteoglycan complex was isolated from human aorta fibrous plaque lesions and LDL-proteoglycan complex was formed in vitro. Both in vitro and in vivo complexes stimulated cholesteryl ester synthesis in foam cells by a dose-dependent, saturable process that resulted in the intracellular accumulation of cholesteryl ester. Stimulation of cholesteryl ester synthesis was linear with time over a 32-h period. Polyinosinic acid inhibited the stimulation of cholesteryl ester synthesis by the complexes by $32-37 \%$, whereas cytochalasin D only produced a 6-16\% inhibition. Foam cells degraded ${ }^{125} \mathrm{I}-\mathrm{LDL}$-proteoglycan complex and ${ }^{125}$ I-acetyl LDL in a saturable, dose-dependent manner. Excess unlabeled acetyl-LDL inhibited the degradation of ${ }^{125}$ I-LDL-proteoglycan complex by $52 \%$, while LDL had no effect. Similarly, excess unlabeled complex suppressed the degradation of ${ }^{125}$ I-acetyl-LDL by $48 \%$. Foam cells degraded ${ }^{125}$ Imethyl-LDL-proteoglycan complex to the same extent as ${ }^{125} \mathrm{I}$ LDL-proteoglycan complex. These results show that foam cells from atherosclerotic lesions metabolize lipoprotein-proteoglycan complexes predominantly via receptor-mediated endocytosis and consequently continue to accumulate intracellular cholesteryl ester. (J. Clin. Invest. 1993. 91:1011-1018.) Key words: rabbit aorta foam cells $\bullet$ lipoprotein-proteoglycan complex uptake - cholesteryl ester accumulation • receptor pathway • atherosclerosis
\end{abstract}

\section{Introduction}

Foam cells of atherosclerotic lesions originate predominantly from macrophages (1-5). It is well recognized that the cholesteryl ester that accumulates in foam cells is derived from LDL; however, the in vivo mechanism of LDL-mediated cholesteryl ester accumulation in macrophages is not known. In vitro, macrophages accumulate cholesteryl ester when exposed to acetylLDL (6), malondialdehyde modified LDL (7), oxidized LDL

Address correspondence to Dr. Gerald S. Berenson, Department of Applied Health Sciences, Tulane School of Public Health \& Tropical Medicine, 1501 Canal St., 14th Floor, New Orleans, LA 70112-2824.

Received for publication 22 April 1992 and in revised form $31 \mathrm{Au}$ gust 1992

J. Clin. Invest.

(c) The American Society for Clinical Investigation, Inc

$0021-9738 / 93 / 03 / 1011 / 08 \quad \$ 2.00$

Volume 91, March 1993, 1011-1018
(8), LDL isolated from atherosclerotic lesions (9), and aggregated LDL (10), but not native LDL.

Several studies including our own have shown that complexes of LDL and arterial wall proteoglycan also promote cholesteryl ester accumulation in macrophages in vitro (11-14). The demonstration of the existence of lipoprotein-proteoglycan complexes in vivo and their successful isolation from atherosclerotic lesions in humans and animals $(15,16)$ have led to the hypothesis that the uptake of such complexes by macrophages could cause foam cell formation in vivo. Our recent studies have provided support to this hypothesis (17). Apo B-lipoprotein-proteoglycan complexes isolated from fatty streaks and fibrous plaques of human aorta were taken up by human monocyte-derived macrophages and consequently induced cellular cholesteryl ester synthesis and accumulation.

In an attempt to obtain further experimental evidence in support of this hypothesis, we have turned to the foam cells. Foam cells isolated from atherosclerotic lesions take up chemically modified LDL and apo E-containing lipoproteins (1820 ). In contrast, very little native LDL is metabolized by these cells (20). The uptake of lipoprotein-proteoglycan complexes by foam cells followed by stimulation of cholesteryl ester formation would strongly indicate a role for proteoglycans in foam cell formation. Therefore, in this study we have investigated the metabolism of lipoprotein-proteoglycan complexes by freshly isolated foam cells from atherosclerotic lesions of rabbit aorta. The results show that these complexes are taken up by rabbit aorta foam cells by a receptor-mediated mechanism and they stimulate further intracellular accumulation of cholesteryl ester.

\section{Methods}

\section{Materials}

Opti-MEM I reduced serum media was obtained from GIBCO BRL (Gaithersburg, MD). Collagenase (CLSPA) came from Worthington Biochemical Corp. (Freehold, NJ) and elastase (type III), soybean trypsin inhibitor, and Percoll from Sigma Immunochemicals (St. Louis, MO). Tissue culture plastics were purchased from Costar Corp. (Cambridge, MA) and anti-rabbit macrophage monoclonal antibody RAM-11 from Dako Corp. (Carpinteria, CA).

\section{Lipoproteins}

LDL $(d=1.02-1.055 \mathrm{~g} / \mathrm{ml})$ was isolated from pooled human serum by sequential ultracentrifugation (21). $0.05 \%$ EDTA, $10 \mu \mathrm{M}$ butylated hydroxytoluene, and $20 \mathrm{mM}$ PMSF were added to the blood immediately after collection. The purity of LDL was determined by agarose gel electrophoresis. LDL was acetylated by the repeated addition of acetic anhydride (22), which modified $91 \%$ of available free amino groups. Reductive methylation of LDL was performed as described by Weisgraber et al. (23). This modified $82 \%$ of available free amino groups. Aggregated LDL was prepared by vortexing LDL for $30 \mathrm{~S}$ (10). Lipoproteins were radiolabeled with carrier free $\mathrm{Na}^{125} \mathrm{I}$ (24). 


\section{Proteoglycan}

A chondroitin sulfate-dermatan sulfate proteoglycan aggregate was prepared from bovine aorta. The isolation and characterization of the proteoglycan has been reported previously (11). Briefly, bovine aorta intima-media slices were extracted with $0.5 \mathrm{M}$ guanidine hydrochloride in the presence of protease inhibitors. The extract was subjected to $\mathrm{CsCl}$ isopycnic density gradient centrifugation at a loading density of $1.60 \mathrm{~g} / \mathrm{ml}$. The bottom two-fifths of the gradient represented proteoglycan aggregate. The aggregate contained $18 \%$ hyaluronic acid, $19 \%$ dermatan sulfate, and $63 \%$ chondroitin sulfate.

\section{Lipoprotein-proteoglycan complexes}

In vitro complexes. Complexes of LDL or ${ }^{125} \mathrm{I}-\mathrm{LDL}$ and the proteoglycan aggregate were prepared essentially as described previously (25). In brief, $0.1 \mathrm{ml}$ of proteoglycan solution ( $18.2 \mu \mathrm{g}$ uronic acid or $60 \mu \mathrm{g}$ glycosaminoglycan ) was mixed with LDL or ${ }^{125} \mathrm{I}-\mathrm{LDL}$ ( $150 \mu \mathrm{g}$ cholesterol). $\mathrm{CaCl}_{2}$ (final concentration $30 \mathrm{mM}$ ) was added to the mixture followed by appropriate volumes of $0.001 \mathrm{M}$ Tris- $\mathrm{HCl}, \mathrm{pH} 7.4$, to bring the final volume to $1.5 \mathrm{ml}$. After $15 \mathrm{~min}$ at room temperature, the precipitated LDL-proteoglycan complex was sedimented by centrifugation $(8,000 \mathrm{~g}$ for $5 \mathrm{~min})$. The complex was solubilized in the foam cell culture medium (see below) and filtered through a $0.45-\mu \mathrm{M}$ filter before use in various experiments. Cholesterol and uronic acid contents of the complex were assayed and used as measures of LDL and proteoglycan, respectively. Almost all of the LDL and $80 \%$ of the proteoglycan were recovered in the complex.

In vivo complex. Lipoprotein-proteoglycan complex was isolated from fibrous plaque lesions of human aorta. Details of the isolation and purification procedures have been reported (17). Briefly, human aortas were obtained at autopsy within $12 \mathrm{~h}$ of death. Fibrous plaque lesions from four to five aortas were pooled and extracted with $0.15 \mathrm{M}$ $\mathrm{NaCl}$ and $0.05 \mathrm{M}$ Tris- $\mathrm{HCl}, \mathrm{pH} 7.4$, containing protease inhibitors $(0.1$ $\mathrm{M}$ e-amino- $n$-caproic acid, $0.005 \mathrm{M}$ benzamidine hydrochloride, 0.005 M $N$-ethylmaleimide, $0.001 \mathrm{M}$ PMSF), and antioxidants $(0.05 \%$ EDTA, $20 \mu \mathrm{M}$ butylated hydroxytoluene). Fractionation of the extract on a column of Bio-Gel A-50m yielded two complexes containing both lipoprotein and proteoglycan, one eluting at the $V_{0}$ (complex 1$)$ and the other eluting in the inclusive volume ahead of human LDL (complex 2); lipoprotein-proteoglycan complex 2 was further purified by anti-apoB-affinity chromatography and used in this study.

\section{Foam cells}

Foam cells were prepared by a modification of the procedures described previously $(20,26) .46$ male New Zealand white rabbits weighing 2-2.3 kg were fed a high cholesterol ( $2 \%$ ) diet for $1 \mathrm{wk}$. The aorta and left iliac artery of each animal were deendothelialized with a Fogarty embolectomy catheter and the rabbits were continued on the high cholesterol diet for an additional 12 wk. Recently, Rosenfeld et al. reported that this procedure improved the yield of foam cells (20). Rabbits were killed by intravenous injection of sodium pentobarbital and aortas and left iliac arteries were quickly transferred to sterile HBSS containing glucose, amino acids, and antibiotics (26).

Atherosclerotic lesions, which covered almost the entire vessel surface, were dissected aseptically and chopped into $\sim 0.5-\mathrm{mm}$ pieces. The tissue pieces were placed in fresh Hanks' solution with the supplements in which the calcium concentration had been reduced to 0.2 $\mathrm{mM}(10 \mathrm{ml} / \mathrm{g}$ tissue $)$. The lesions were digested with a mixture of collagenase $(600 \mathrm{U} / \mathrm{ml})$, elastase $(5 \mathrm{U} / \mathrm{ml})$, and soybean trypsin inhibitor $(1 \mathrm{mg} / \mathrm{ml})$ at $37^{\circ} \mathrm{C}$ with shaking for $30 \mathrm{~min}$. The enzyme-tissue mixture was filtered through a $100-\mu \mathrm{m}$ mesh nylon screen (Whatman Inc., Clifton, NJ) in a Swinex filter holder (Millipore Corp.; Bedford, MA). The tissue chunks on the filter were returned to the digestion flask. The filtrate was centrifuged at $2,300 \mathrm{rpm}$ for $5 \mathrm{~min}$ in a desk top centrifuge (model TJ-6; Beckman Instruments, Inc., Fullerton, CA) and the supernatant was returned to the digestion flask. The cells from the centrifugation were washed with supplemented Hanks' solution containing $10 \%$ fetal bovine serum and kept in supplemented Hanks' solution at $37^{\circ} \mathrm{C}$. The remaining tissue was digested for $30 \mathrm{~min}$ and cells were separated and washed as before. This procedure was repeated five times. The cells from all digestions were combined and pelleted by centrifugation. The cell pellet was resuspended in 1-2 ml of $90 \%$ Percoll in calcium- and magnesium-free Hanks' solution and layered under a preformed gradient of $40 \%$ Percoll in calcium- and magnesium-free Hanks' solution (27). The solution was centrifuged at $400 \mathrm{~g}$ for $20 \mathrm{~min}$ in a swinging bucket rotor (model TH-4; Beckman Instruments, Inc.). The top fraction $(d<1.06 \mathrm{~g} / \mathrm{ml})$ containing exclusively the foam cells was removed and the cells were washed with Opti-MEM I containing $0.5 \%$ fetal bovine serum (medium A). The cells were plated in the above medium in 24-well dishes at a density of $5 \times 10^{5}$ cells/well and incubated at $37^{\circ} \mathrm{C}$ in a humidified $\mathrm{CO}_{2}(5 \%)$ incubator. Nonadherent cells were washed off the wells after $24 \mathrm{~h}$ and the adherent foam cells were used immediately for the experiments. Viability of the cells was assessed by their ability to exclude trypan blue. The purity of the foam cells was established by immunohistochemical staining with anti-rabbit macrophage monoclonal antibody RAM-11 (28).

\section{Macrophages}

Human monocyte-derived macrophages were isolated as described previously (17). The monocytes were cultured in RPMI-1640 containing $20 \%$ homologus serum ( $\mathrm{vol} / \mathrm{vol}$ ), penicillin $(100 \mathrm{U} / \mathrm{ml}$ ), and streptomycin $(100 \mu \mathrm{g} / \mathrm{ml})$. The cells were maintained in culture for $8 \mathrm{~d}$ with medium changes every $3 \mathrm{~d}$ before they were used for experiments.

\section{Cholesterol esterification}

The ability of various ligands to stimulate cholesteryl ester synthesis in foam cells was determined essentially as described previously (11). Briefly, foam cells were incubated in medium A containing $0.2 \mathrm{mM}$ $\left[{ }^{14} \mathrm{C}\right]$ oleate-albumin and different ligands for $16 \mathrm{~h}$ at $37^{\circ} \mathrm{C}$. For time course studies, the incubations ranged from 4 to $32 \mathrm{~h}$. Cellular lipids were extracted and separated by thin layer chromatography. Cholesteryl ester spots were identified from the position of cholesteryl oleate standard and scraped off the plate. Cholesteryl ester content was quantified by liquid scintillation spectrometer. Results were corrected for the percent recovery of an internal $\left[{ }^{3} \mathrm{H}\right]$ cholesteryl oleate standard. The solvent-extracted cells were dissolved in $0.5 \mathrm{ml}$ of $0.2 \mathrm{M} \mathrm{NaOH}$ and an aliquot was used for protein assay.

\section{Cholesteryl ester accumulation}

For cellular cholesterol mass determination, foam cells were incubated with various ligands for $48 \mathrm{~h}$. [ $\left.{ }^{3} \mathrm{H}\right]$ Cholesterol was then added as an internal standard and cellular lipids were extracted with hexane/isopropanol (3:2, vol/vol). Cholesterol and cholesteryl ester were separated by thin layer chromatography and quantitated by the procedure of Bowman and Wolf (29) with the modification that the chromophore was measured spectrofluorometrically.

\section{Degradation of ${ }^{125}$ I-labeled ligands}

Cellular degradation of various ${ }^{125} \mathrm{I}$-labeled ligands was assayed as described previously (11). Foam cells were incubated in medium A containing ${ }^{125}$ I-labeled ligands and other additions as required by individual experiments. After $6 \mathrm{~h}$ at $37^{\circ} \mathrm{C}$, the culture medium was assayed for trichloroacetic acid soluble (noniodide) radioactivity. Results were corrected for small amounts of acid-soluble radioactivity formed in parallel cell-free incubations.

\section{Analytical methods}

Uronic acid was assayed by the method of Blumenkrantz and AsboeHansen ( 30 ) and protein by a modified Lowry procedure (31). Cholesterol determination was done with a commercial enzymatic reagent kit (Autoflow Cholesterol 236691; Boehringer Mannhein Diagnostics, Houston, TX). Other assays were done as described previously (17). 

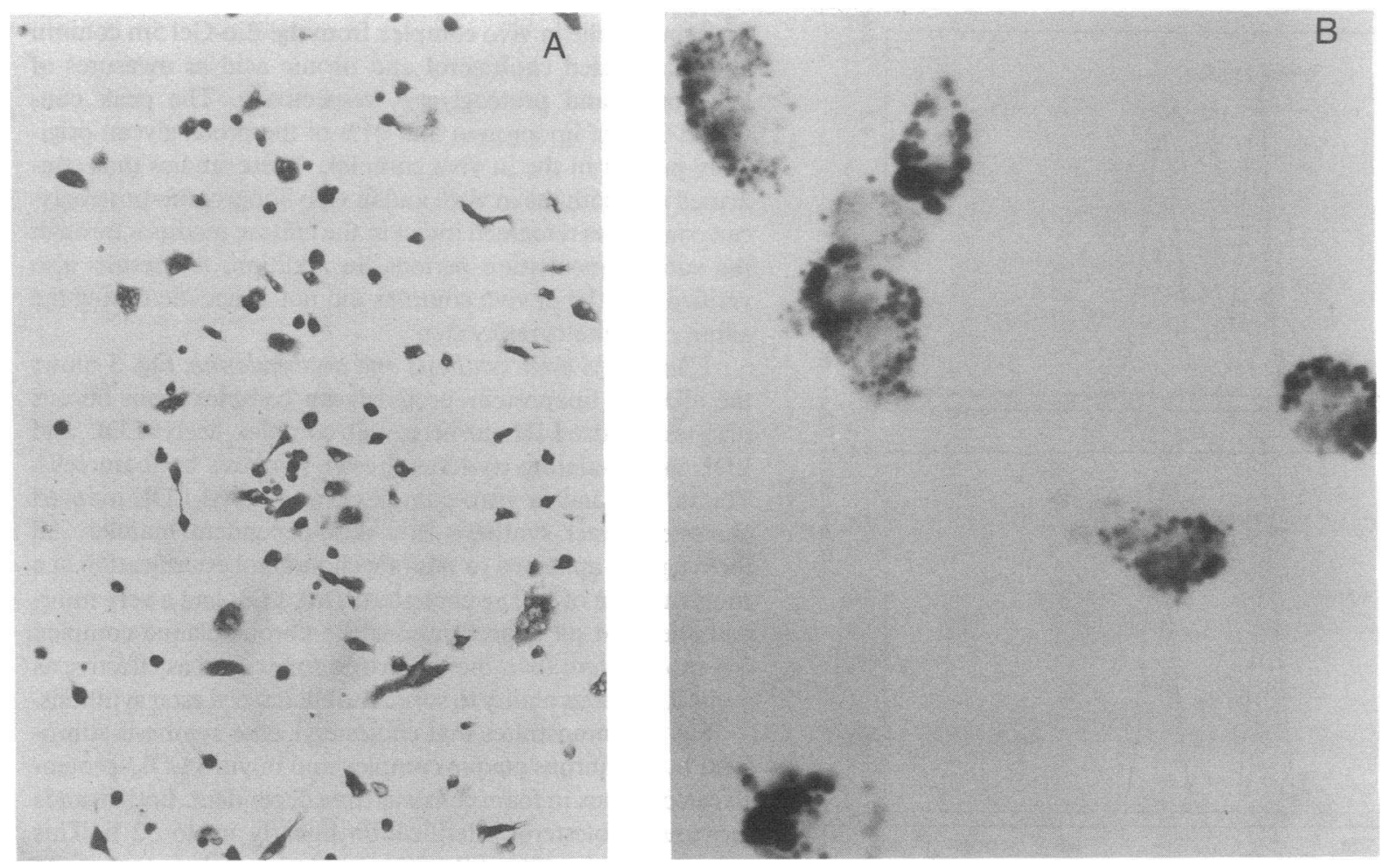

Figure 1. (A) Immunohistochemical staining of rabbit aorta foam cells. Foam cells were plated on slides. After overnight incubation, the cells were immunostained with anti-rabbit macrophage monoclonal antibody RAM-11 and detected with avidin-biotin system conjugated with horseradish peroxidase. The cells were photographed with an Olympus photomicroscope. Phase contrast; final magnification 100 . (B) Light photomicrograph of oil red O-stained foam cells. Final magnification 400.

\section{Results}

\section{Isolation and characterization of foam cells}

46 rabbits were used in the study. During the course of the 13-wk period, six rabbits died due to middle ear infection. Cholesterol feeding produced marked hypercholesterolemia (average cholesterol $1,250 \pm 112 \mathrm{mg} / \mathrm{dl}$ ) in the remaining 40 rabbits.

The cells obtained by the Percoll gradient technique were entirely foam cells of macrophage lineage as evidenced by their immunoreactivity with macrophage-specific monoclonal antibody RAM-11 (Fig. $1 \mathrm{~A}$ ). This antibody did not stain smooth muscle cells isolated from rabbit aorta. The average yield of cells was $2.5 \times 10^{6}$ cells per gram of aorta. Cell viability varied between 89 and $94 \%$. The cells contained a large number of oil red O-positive lipid droplets (Fig. $1 B$ ), which were due to massive intracellular cholesterol deposits. The free and esterified cholesterol contents of the cells were $110 \pm 23$ and $420 \pm 36$ $\mu \mathrm{g} / \mathrm{mg}$ protein, respectively ( mean \pm SD of four separate assays, each in triplicate). There was no significant loss of cellular cholesterol when the cells were incubated in Opti-MEM I containing $0.5 \%$ serum for up to $7 \mathrm{~d}$.

\section{Characterization of in vivo lipoprotein-proteoglycan complex}

Recently we reported detailed characterization of the in vivo lipoprotein-proteoglycan complex isolated from fibrous plaque lesions (17). The affinity-purified complex used in this study contained $24 \%$ protein, $9 \%$ free cholesterol, $36 \%$ esterified cholesterol, $14 \%$ phospholipids, $7 \%$ triglycerides, and $10 \%$ uronic acid. The complex showed positive immunoreactivity against anti-human fibronectin antibody but not against antihuman albumin antibody or anti-human IgG. Apo B, determined by electroimmunoassay, accounted for $48 \%$ of the total protein. What percentage of the remainder represented modified apo B devoid of immunoreactivity $(32,33)$ and fibronectin was not determined. The complex did not contain immunoreactive apolipoproteins C-I, C-II, C-III, and A-I. The glycosaminoglycan composition of the complex was $26 \%$ heparin, $20 \%$ hyaluronic acid, $45 \%$ chondroitin 6 -sulfate, and $9 \%$ dermatan sulfate. As compared with LDL in the in vitro complex, the lipoprotein in the fibrous plaque complex underwent some lipid peroxidation (thiobarbituricacid reactive substances [TBARS] ${ }^{1}$ nanomoles per milligram protein: LDL in in vitro complex, 0.39; lipoprotein in fibrous plaque complex, 1.05). Earlier we reported that there was no significant difference in the TBARS between the complexes isolated from postmortem samples and those isolated immediately from atherosclerotic lesions obtained at surgical resection (17), indicating that the peroxidation results probably from changes associated with the pathogenesis of atherosclerosis.

\section{Metabolic studies}

Control experiments. The interaction of LDL and proteoglycan is ionic in nature (25). Hence, there existed a possibility that the lipoprotein-proteoglycan complexes might dissociate in

1. Abbreviation used in this paper: TBARS, thiobarbituricacid reactive substances. 

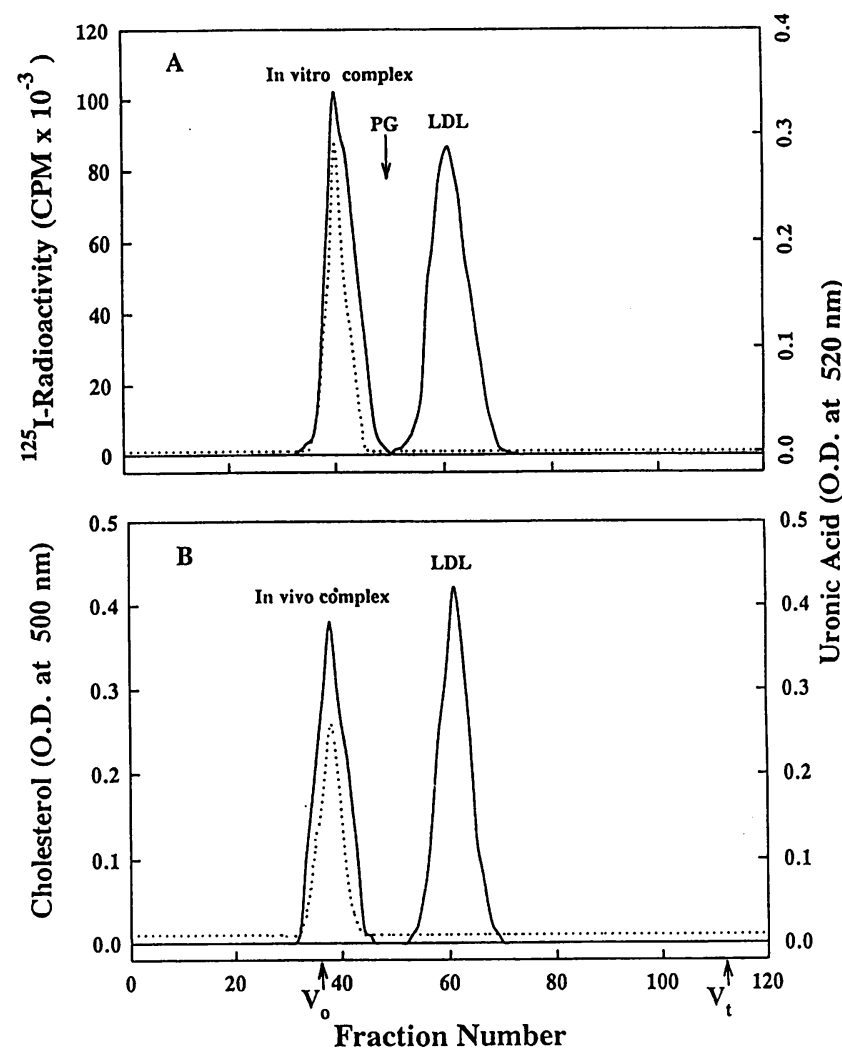

Figure 2. $(A)$ Bio-Gel A-5m chromatography of ${ }^{125} \mathrm{I}-\mathrm{LDL}$ and in vitro ${ }^{125}$ I-LDL-proteoglycan complex. ${ }^{125} \mathrm{I}$-LDL-proteoglycan complex was formed and dissolved in $1 \mathrm{ml}$ of medium A. The solution was incubated at $37^{\circ} \mathrm{C}$ for $40 \mathrm{~h}$ along with ${ }^{125} \mathrm{I}-\mathrm{LDL}$ (in medium A). Both ${ }^{125} \mathrm{I}-\mathrm{LDL}$ and ${ }^{125} \mathrm{I}-\mathrm{LDL}$-proteoglycan complex were then eluted on a Bio-Gel A-5m column $(1.5 \times 90 \mathrm{~cm})$ with $0.15 \mathrm{M} \mathrm{NaCl}, 0.05 \mathrm{M}$ Tris- $\mathrm{HCl}, \mathrm{pH} \mathrm{7.4,} \mathrm{at} \mathrm{a} \mathrm{flow} \mathrm{rate} \mathrm{of} 12 \mathrm{ml} / \mathrm{h}$. Fractions of $1 \mathrm{ml}$ were collected and analyzed for ${ }^{125} \mathrm{I}$ radioactivity and uronic acid. The elution position of proteoglycan $(P G)$ is indicated by the arrow. $(B)$ Bio-Gel A-5m chromatography of $\mathrm{LDL}$ and in vivo fibrous plaque complex. LDL and affinity-purified fibrous plaque complex were incubated in medium $\mathrm{A}$ for $40 \mathrm{~h}$ at $37^{\circ} \mathrm{C}$. They were then eluted on the Bio-Gel column as described for the in vitro complex. Fractions were analyzed for cholesterol and uronic acid as measures of lipoprotein and proteoglycan, respectively.

solutions of physiologic ionic strength. It was therefore necessary to establish that both the in vitro and in vivo complexes remained intact after adding to the incubation medium for foam cells. This was done as follows: An in vitro complex of ${ }^{125}$ I-LDL and proteoglycan was formed and dissolved in medium A. The solution was incubated at $37^{\circ} \mathrm{C}$ for $40 \mathrm{~h}$ along with ${ }^{125} \mathrm{I}$-LDL (in the above medium). We then compared their elution profiles on a column of Bio-Gel A-5m. As shown in Fig. $2 A$, the ${ }^{125}$ I-LDL-proteoglycan complex eluted ahead of ${ }^{125} \mathrm{I}$ LDL ( $K_{\text {av }}$-complex 0.02; LDL, 0.29). Proteoglycan (uronic acid) in the complex coeluted with ${ }^{125}$ I-LDL radioactivity. We also performed a similar comparison of the elution profiles of LDL and affinity-purified in vivo lipoprotein-proteoglycan complex from fibrous plaques. The complex was added to medium $A$ and incubated at $37^{\circ} \mathrm{C}$ for up to $40 \mathrm{~h}$ before applying to the Bio-Gel column. As shown in Fig. $2 B$, the in vivo complex had an elution profile similar to the in vitro complex and it eluted before LDL. Once again proteoglycan coeluted with the lipoprotein in the complex. Additionally, we pooled the peak fractions for the in vivo complex from the Bio-Gel $5 \mathrm{~m}$ column and quantitated cholesterol and uronic acid as measures of lipoprotein and proteoglycan, respectively. The peak contained $96 \%$ of lipoprotein and $91 \%$ of the proteoglycan originally present in the in vivo complex. These studies thus confirmed that both the in vitro and in vivo lipoprotein-proteoglycan complexes remained intact in the culture medium through the various incubation periods. In addition, the results also verified that the in vivo complex did not dissociate during the affinity chromatography step.

Cholesteryl ester synthesis and accumulation. Fig. 3 shows the effect of lipoprotein-proteoglycan complex from fibrous plaques, in vitro LDL-proteoglycan complex, acetyl-LDL, and LDL in stimulating cholesteryl ester synthesis by foam cells. The in vivo and in vitro complexes and acetyl-LDL induced cholesteryl ester synthesis in a dose-dependent manner. All three ligands appeared to saturate cholesterol esterification at a concentration of $100 \mu \mathrm{g}$ cholesterol $/ \mathrm{ml}$. LDL had a very minimal effect. At all concentrations the fibrous plaque complex was more potent than the in vitro complex, and as effective as acetyl-LDL in its ability to stimulate cholesteryl ester synthesis.

Fig. 4 demonstrates that cholesteryl ester synthesis stimulated by the fibrous plaque complex and in vitro LDL-proteoglycan complex in foam cells was time dependent. Both ligands increased cholesterol esterification linearly up to $32 \mathrm{~h}$. This indicates that in spite of the massive cholesterol content of the foam cells, their uptake of the lipoprotein-proteoglycan complexes was not downregulated over this period. Once again, the in vivo fibrous plaque complex induced a greater stimulation of cholesteryl ester synthesis than the in vitro complex.

In the above experiments it is possible that during the prolonged incubation period (16-32 h) secretory products from cells could modify the lipoprotein in the complexes and thereby influence their cellular uptake. To verify this, we incubated the in vitro and in vivo lipoprotein-proteoglycan complexes with human monocyte-derived macrophages for $32 \mathrm{~h}$. The lipoprotein was then isolated from the complexes by dissociative ultracentrifugation (17). We then determined the extent of peroxidation of the lipoprotein. Exposure of the com-

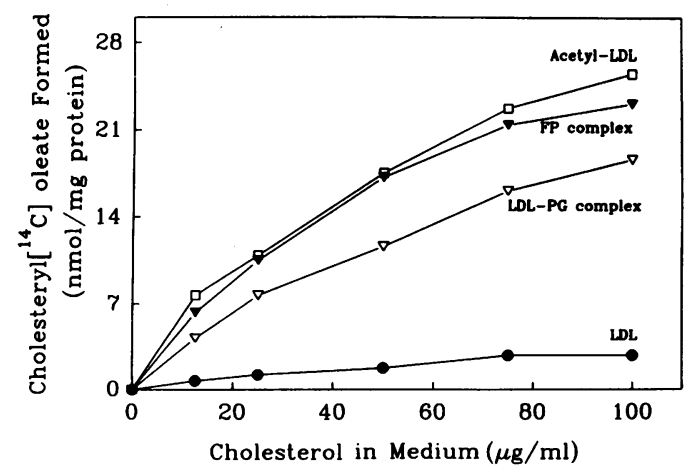

Figure 3. Cholesteryl ester synthesis in rabbit aorta foam cells incubated with in vitro LDL-proteoglycan complex, in vivo fibrous plaque complex, LDL, and acetyl-LDL. Foam cells were incubated in medium A containing the indicated concentrations of in vitro LDL-proteoglycan complex ( $L D L-P G$ complex), in vivo fibrous plaque complex (FP complex), LDL or acetyl-LDL, and $0.2 \mathrm{mM}$ $\left[{ }^{14} \mathrm{C}\right]$ oleate-albumin. After $16 \mathrm{~h}$ at $37^{\circ} \mathrm{C}$, the cellular content of cholesteryl $\left[{ }^{14} \mathrm{C}\right]$ oleate was determined. Each data point represents the mean of three separate experiments, each in triplicate. 


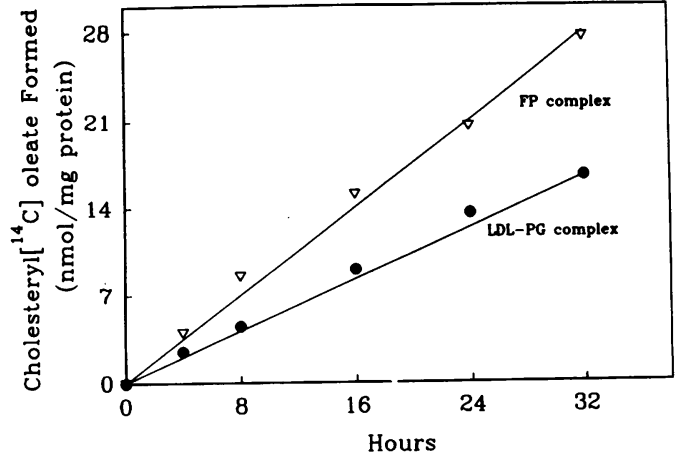

Figure 4. Stimulation of cholesteryl ester synthesis in foam cells by fibrous plaque complex and in vitro LDL-proteoglycan complex as a function of time. Monolayers of foam cells were incubated with 50 $\mu \mathrm{g}$ cholesterol/ $\mathrm{ml}$ of fibrous plaque complex or in vitro LDL-proteoglycan complex and $0.2 \mathrm{mM}\left[{ }^{14} \mathrm{C}\right]$ oleate-albumin. At the indicated time the cellular content of cholesteryl $\left[{ }^{14} \mathrm{C}\right]$ oleate was determined. The data represent the average of triplicate assays.

plexes to macrophages increased oxidation of the lipoproteins as compared with lipoproteins obtained from complexes not exposed to cells (TBARS, nanomoles per milligram protein: in vitro complexes, 0.59 vs. 0.42 ; in vivo complexes, 1.56 vs. 1.02 ).

The stimulation of cholesteryl ester synthesis by the lipoprotein-proteoglycan complexes and acetyl-LDL resulted in an increase in the cellular cholesteryl ester content (Table I). Incubation of foam cells for $48 \mathrm{~h}$ with $100 \mu \mathrm{g}$ cholesterol $/ \mathrm{ml}$ of fibrous plaque complex, in vitro LDL-proteoglycan complex, or acetyl-LDL increased their cholesteryl ester content by 74 , 55 , and $81 \%$, respectively, above control cells. The corresponding increase in cellular free cholesterol was 70,44 , and $91 \%$, respectively.

Effect of polyinosinic acid and cytochalasin D on cholesteryl ester synthesis. In an attempt to determine the mechanism of uptake of lipoprotein-proteoglycan complexes in foam cells, we investigated the effect of polyinosinic acid, a specific inhibitor of acetyl-LDL (scavenger) receptor, and cytochalasin D, an inhibitor of phagocytosis, on the stimulation of cholesteryl ester synthesis. As shown in Fig. 5, polyinosinic acid inhibited

Table I. Free and Esterified Cholesterol Content of Foam Cells Incubated with Fibrous Plaque Complex, In Vitro LDL-Proteoglycan Complex, or Acetyl-LDL

\begin{tabular}{lcc}
\hline \multicolumn{1}{c}{ Additions } & $\begin{array}{c}\text { Free } \\
\text { cholesterol }\end{array}$ & $\begin{array}{c}\text { Esterified } \\
\text { cholesterol }\end{array}$ \\
\hline & \multicolumn{2}{c}{$\mu g / m g$ protein } \\
None & 97 & 392 \\
Fibrous plaque complex & 165 & 684 \\
In vitro LDL-proteoglycan complex & 140 & 610 \\
Acetyl-LDL & 186 & 710 \\
\end{tabular}

Foam cells were incubated in medium A alone or medium A containing $100 \mu \mathrm{g}$ cholesterol/ml of fibrous plaque complex, in vitro LDL-proteoglycan complex, or acetyl-LDL. After $24 \mathrm{~h}$ at $37^{\circ} \mathrm{C}$, the medium was removed and replaced with medium of identical composition. After an additional $24 \mathrm{~h}$ the cellular lipids were extracted and free and esterified cholesterol were quantitated. Each value represents the average of quadruplicate assays.

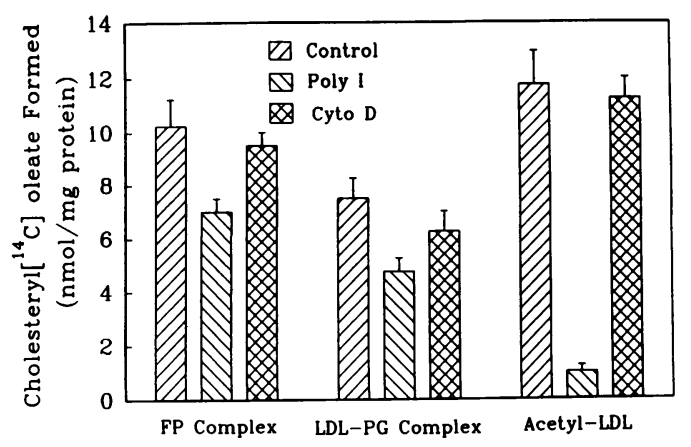

Figure 5. Effect of polyinosinic acid and cytochalasin D on cholesteryl ester synthesis mediated by fibrous plaque complex, in vitro LDL-proteoglycan complex, and acetyl-LDL. Foam cells were incubated with $25 \mu \mathrm{g}$ cholesterol $/ \mathrm{ml}$ of fibrous plaque complex, in vitro LDL-proteoglycan complex, or acetyl-LDL and $0.2 \mathrm{mM}\left[{ }^{14} \mathrm{C}\right]-$ oleate-albumin in the presence and absence of polyinosinic acid (Poly I; $50 \mu \mathrm{g} / \mathrm{ml}$ ) or cytochalasin D (Cyto D; $2 \mu \mathrm{g} / \mathrm{ml}$ ). After $16 \mathrm{~h}$ at $37^{\circ} \mathrm{C}$, cholesteryl $\left[{ }^{14} \mathrm{C}\right.$ ] oleate formed was quantitated. Data represent the mean $\pm \mathrm{SD}$ of two experiments, each in duplicate.

cholesteryl ester synthesis induced by fibrous plaque complex and in vitro LDL-proteoglycan complex by 32 and $37 \%$, respectively. In contrast, the drug completely inhibited acetyl-LDLmediated cholesteryl ester synthesis. Cytochalasin $\mathrm{D}(2 \mu \mathrm{g} / \mathrm{ml})$ had no effect on cholesteryl ester formation elicited by acetylLDL, and it inhibited cholesteryl ester formation stimulated by fibrous plaque complex and the in vitro complex by only 6 and $16 \%$, respectively. In contrast, the drug inhibited the degradation of aggregated LDL by $90 \%$ (data not shown). These results thus suggest that while the scavenger receptor might be involved in the recognition of the complexes, phagocytosis plays no significant role.

Degradation of ${ }^{125} I-L D L-$ proteoglycan complex. To understand further the mechanism of recognition of the complexes, we then studied the degradation of ${ }^{125}$ I-LDL-proteoglycan complex by foam cells (Fig. 6 ). The cells degraded ${ }^{125}$ I-LDL-

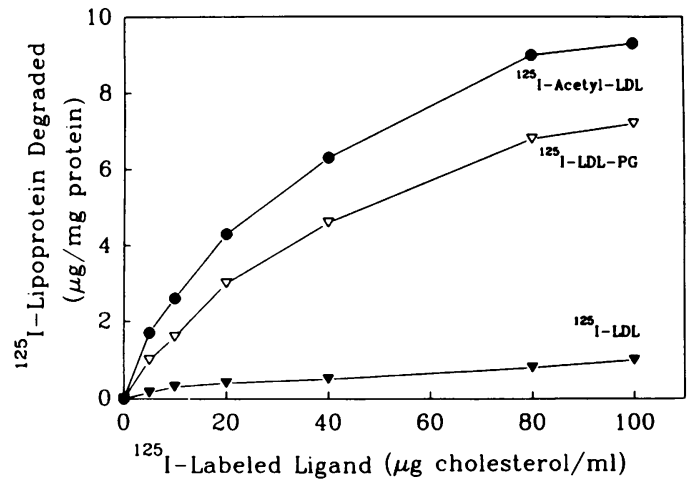

Figure 6. Degradation of ${ }^{125} \mathrm{I}-\mathrm{LDL}$-proteoglycan complex, ${ }^{125} \mathrm{I}-\mathrm{LDL}$, and ${ }^{125}$ I-acetyl LDL by foam cells. Monolayers of adherent foam cells were incubated with the indicated concentrations of ${ }^{125} \mathrm{I}-\mathrm{LDL}-$ proteoglycan complex ( $\left.{ }^{125} I-L D L-P G\right),{ }^{125} \mathrm{I}-\mathrm{LDL}$, or ${ }^{125} \mathrm{I}$-acetyl-LDL in the presence and absence of $500 \mu \mathrm{g}$ cholesterol $/ \mathrm{ml}$ of the corresponding unlabeled ligand. After $6 \mathrm{~h}$ at $37^{\circ} \mathrm{C}$, degradation of each ligand was determined and specific degradation calculated by subtracting the micrograms degraded in the presence of excess unlabeled ligand from that obtained in the absence of unlabeled ligand. Each data point represents the mean of three experiments, each in duplicate. 
proteoglycan complex and ${ }^{125}$ I-acetyl-LDL in a dose-dependent manner. Degradation of both ligands appeared to reach saturation at $100 \mu \mathrm{g}$ cholesterol $/ \mathrm{ml}$. The cells degraded very little ${ }^{125}$ I-LDL.

In studies to be published elsewhere (Vijayagopal, P., S. R. Srinivasan, B. Radhakrishnamurthy, and G. S. Berenson, manuscript submitted for publication), we performed binding studies of ${ }^{125}$ I-LDL-proteoglycan complexes to human monocyte-derived macrophages at $4^{\circ} \mathrm{C}$. Binding was concentration dependent and saturable. Scatchard analysis of the data gave a $K_{\mathrm{d}}$ of $1.5 \times 10^{-8} \mathrm{M}$, which was 1.75 times higher than the $K_{\mathrm{d}}$ reported for LDL in macrophages (34).

Having established that the foam cells degrade a significant amount of ${ }^{125} \mathrm{I}$-LDL-proteoglycan complex, we then performed competitive degradation experiments using other ligands. The results are presented in Table II. A 50-fold excess of unlabeled acetyl-LDL inhibited the catabolism of ${ }^{125}$ I-LDLproteoglycan complex by $52 \%$. Excess unlabeled LDL had no effect. In contrast, a 50-fold excess of unlabeled LDL-proteoglycan complex inhibited the degradation of the labeled complex by $92 \%$. In the reverse competition experiment, excess LDL-proteoglycan complex suppressed the degradation of ${ }^{125}$ I-acetyl LDL by $48 \%$. Neither excess complex nor acetylLDL inhibited the degradation of ${ }^{125}$ I-LDL (data not shown). These results further emphasized a role for the scavenger receptor in the uptake of lipoprotein-proteoglycan complexes in foam cells.

Earlier, we reported that excess proteoglycan and hyaluronic acid did not inhibit the binding and degradation of ${ }^{125}$-ILDL-proteoglycan complex in macrophages $(35,36)$.

Degradation of ${ }^{125}$ I-methyl LDL-proteoglycan complex. The lack of competition by LDL against the degradation of ${ }^{125}$ I-LDL-proteoglycan complex suggested that the uptake of the complex was not through the apo B, E receptor. To further confirm this, we studied the degradation of ${ }^{125} \mathrm{I}$-methyl-LDLproteoglycan complex by foam cells. While methylation of LDL inhibits uptake via the apo B, E receptor pathway (23), it does not interfere with proteoglycan interaction (35). The cells degraded ${ }^{125}$ I-methyl-LDL-proteoglycan complex to the same extent as ${ }^{125}$ I-LDL-proteoglycan complex (data not shown).

Table II. Effect of Excess Unlabeled Ligands on the Degradation of ${ }^{125}$ I-LDL-Proteoglycan Complex and ${ }^{125}$ I Acetyl-LDL by Foam Cells

\begin{tabular}{lcr}
\hline & \multicolumn{2}{c}{${ }^{125}$ I-Ligand degraded } \\
\cline { 2 - 3 } \multicolumn{1}{c}{$\begin{array}{c}\text { Unlabeled competitor } \\
\text { ligand }\end{array}$} & $\begin{array}{c}{ }^{125} \text { I-LDL-proteoglycan } \\
\text { complex }\end{array}$ & ${ }^{125}$ I-Acetyl-LDL \\
\hline \multicolumn{2}{c}{$\mu g / m g$ protein } \\
None & $1.8 \pm 0.32$ & $2.4 \pm 0.21$ \\
LDL & $2.1 \pm 0.25$ & $2.5 \pm 0.18$ \\
LDL-proteoglycan complex & $0.15 \pm 0.12$ & $1.24 \pm 0.05$ \\
Acetyl-LDL & $0.87 \pm 0.04$ & $0.06 \pm 0.02$ \\
\hline
\end{tabular}

Foam cells were incubated in medium A containing $10 \mu \mathrm{g}$ cholesterol/ml of ${ }^{125} \mathrm{I}-\mathrm{LDL}$-proteoglycan complex or ${ }^{125} \mathrm{I}$-acetyl-LDL in the presence or absence of a 50 -fold excess $(500 \mu \mathrm{g}$ cholesterol $/ \mathrm{ml})$ of various unlabeled ligands. After $6 \mathrm{~h}$ at $37^{\circ} \mathrm{C}$, cellular degradation of ${ }^{125}$ I-labeled ligand was determined. Each value is the mean \pm SD of two separate experiments, each in triplicate.
These data further ruled out a role for the apo B, E receptor in the uptake of the complexes in these cells.

\section{Discussion}

These studies show that foam cells isolated from atherosclerotic rabbit aortas metabolize intact lipoprotein-proteoglycan complexes. The uptake of the complexes was dose dependent and saturable, indicating that the process is receptor mediated. This caused stimulation of cholesteryl ester synthesis and deposition. Thus, despite the massive cellular cholesterol content of the foam cells, their uptake of lipoprotein-proteoglycan complexes was not downregulated. The lack of downregulation does not appear to be due to alterations in the surface properties of the foam cells caused by the enzymes used for cell isolation. This is because as reported recently by Rosenfeld et al. (20) and confirmed here, the use of collagenase and elastase for foam cell isolation did not destroy the cellular apo $\mathrm{B}, \mathrm{E}$ receptors and scavenger receptors, or the Fc and C3 receptors (2).

It appears that the acetyl-LDL receptor is involved in the uptake of lipoprotein-proteoglycan complexes in rabbit foam cells. Support for the concept derives from the data that excess acetyl-LDL inhibited the degradation of ${ }^{125} \mathrm{I}$-LDL-proteoglycan complex by $52 \%$. However, since the competition was incomplete, it implies that in foam cells the LDL-proteoglycan complexes are taken up only partially via the acetyl-LDL receptor. Similar partial recognition of LDL-proteoglycan complexes (36) and oxidized LDL (37) by the acetyl-LDL receptor has been reported in mouse peritoneal macrophages.

The incomplete competition by acetyl-LDL against the degradation of ${ }^{125} \mathrm{I}-\mathrm{LDL}$-proteoglycan complex could result from a stronger affinity of LDL-proteoglycan complex for the acetyl-LDL receptor. In this situation, one would expect competitive inhibition of ${ }^{125} \mathrm{I}$-acetyl-LDL degradation by excess unlabeled LDL-proteoglycan complex. However, the actual inhibition was only $48 \%$, and hence this is an unlikely possibility. Also, since acetylation of LDL completely abolishes its ability to form complexes with proteoglycans (25), excess acetyl-LDL cannot compete with ${ }^{125} \mathrm{I}-\mathrm{LDL}$ for binding to the proteoglycan and cause reduced degradation of the radiolabeled ligand. Therefore, an alternative explanation for the incomplete competition is that rabbit aorta foam cells, similar to mouse peritoneal macrophages (37), express multiple classes of binding sites for modified lipoproteins.

Even though lipoprotein-proteoglycan complexes and acetyl-LDL share some common binding determinants, the binding sites for the two ligands are not identical in foam cells. This is because polyinosinic acid, a potent inhibitor of the binding and degradation of acetyl-LDL, produced only a modest inhibition (32-37\%) of cholesteryl ester synthesis induced by in vitro LDL-proteoglycan complex and in vivo fibrous plaque complex. This is in agreement with our results in mouse peritoneal macrophages (36). Earlier, Basu et al. observed that polyinosinic acid inhibited the degradation of ${ }^{125} \mathrm{I}-\mathrm{LDL}-$ dextran sulfate complex in mouse peritoneal macrophages by only $25 \%$ (38). Taken together, these data provide further support for the concept of multiple classes of scavenger receptors in rabbit foam cells and mouse macrophages for modified lipoproteins.

Phagocytosis appears to play a very minor role in the uptake of lipoprotein-proteoglycan complexes by foam cells. This is because cytochalasin D, an inhibitor of phagocytosis, 
inhibited cholesteryl ester synthesis elicited by the lipoproteinproteoglycan complexes by only $6-16 \%$.

The acetyl-LDL receptor-mediated uptake combined with phagocytosis accounts for $\sim 60 \%$ of the uptake of lipoproteinproteoglycan complexes in foam cells. Other types of scavenger receptors that recognize modified lipoproteins other than acetyl-LDL may mediate the uptake of the other $40 \%$. The present data, however, rule out the possibility that the apo $B, E$ receptor plays a role in the recognition of LDL-proteoglycan complexes in foam cells. This is because LDL did not block the degradation of ${ }^{125}$ I-LDL-proteoglycan complex. Similarly, excess unlabeled complex also did not compete against the degradation of ${ }^{125} \mathrm{I}$-LDL. In addition, cellular degradations of ${ }^{125} \mathrm{I}$-methylLDL-proteoglycan complex and ${ }^{125}$ I-LDL-proteoglycan complex were identical.

That the apo B, E receptor does not mediate the uptake of lipoprotein-proteoglycan complexes in foam cells differs from the results of Hurt et al. (39) in human monocyte macrophages. These investigators reported that LDL-proteoglycan complex is metabolized predominantly via the LDL receptor in these cells. The discrepancy may be due to the nature of the complexes used in the two studies. The use of a high ratio of LDL to proteoglycan in complex formation by Hurt et al. (39) resulted in complexes containing only 2-4 $\mu$ g of glycosaminoglycan per $100 \mu \mathrm{g}$ of apo B protein. Moreover, under the conditions used for complex formation, the complex dissociated when redissolved in the culture medium. Consequently, the properties of LDL such as surface charge and hydrodynamic size remained unchanged. This resulted in the lipoprotein being internalized via the LDL receptor. In contrast, the glycosaminoglycan content of the in vitro and in vivo complexes in our study was 48 and $200 \mu \mathrm{g}$, respectively, per $100 \mu \mathrm{g}$ apo B protein. The complexes did not dissociate when dissolved and incubated in the culture medium. Also, the hydrodynamic size of the lipoprotein increased as a result of its association with a relatively large amount of proteoglycan (Fig. 1). More importantly, since the lysine and arginine residues of LDL are involved in both receptor binding and complex formation with proteoglycan $(25,40,41)$, continued association with proteoglycan effectively blocks the positive charges of LDL and thus prevents cellular uptake via the apo B, E receptor.

We also considered the possibility that the proteoglycan or hyaluronic acid in the complexes might be the ligands carrying the lipoprotein into the cells. However, this was ruled out because earlier we observed that excess proteoglycan and hyaluronic acid did not prevent the binding of ${ }^{125}$ I-LDL-proteoglycan complex in macrophages $(35,36)$.

Fibronectin was identified in the affinity-purified fibrous plaque complex. Earlier, Hoff and Clevidence (42) also identified this protein in large cholesteryl ester-rich particles isolated from human atherosclerotic lesions. A receptor that recognizes fibronectin has been reported on macrophages (43) and probably exists in foam cells as well. The receptor shows greater affinity when fibronectin is complexed to other connective tissue components (43). Falcone and Salisbury (44) have reported that fibronectin stimulates the uptake of LDL-heparincollagen complexes in macrophages. Since the fibrous plaque complexes contain both heparin and chondroitin sulfate proteoglycan, their interaction with fibronectin can facilitate uptake of the complexes in foam cells, probably through binding to the fibronectin receptors. This could provide an additional pathway for the uptake not mediated by the scavenger receptor. Since the in vitro LDL-proteoglycan complex lacks both fibronectin and heparin, this also could explain the fact that stimulation of cholesteryl ester synthesis induced by LDL-proteoglycan complex was less than that of the fibrous plaque complex in foam cells at equivalent cholesterol in the medium.

Compared with the in vitro LDL-proteoglycan complex, the stimulation of cholesteryl ester synthesis mediated by the in vivo fibrous plaque complex was particularly greater during long-term incubation with cells. We found that during prolonged incubation $(32 \mathrm{~h})$ of the in vivo complex with macrophages, an already oxidized lipoprotein in the complex was further oxidized, probably by factors secreted by the cells. Even though the cells also oxidized LDL in the in vitro complex, the extent of oxidation was less compared with the lipoprotein in the in vivo complex. Consequently, uptake of the in vivo complex through the scavenger receptors is augmented by the increased oxidation of its component lipoprotein during longterm incubation with cells.

In summary, these studies show for the first time that foam cells isolated from atherosclerotic lesions metabolize lipoprotein-proteoglycan complexes via receptor-mediated endocytosis, and consequently continue to accumulate cholesteryl ester. Earlier we showed that such complexes isolated from human fatty streaks and fibrous plaques are taken up by human monocyte-derived macrophages, transforming the cells into foam cells (17). Taken together these observations indicate that lipoprotein-proteoglycan complexes play a role not only in the transformation of macrophages into foam cells, but also in the continued maintenance of the foam cells in that state.

\section{Acknowledgments}

We thank Dr. S. Shenoy for help with the balloon embolectomy and Dr. Larry Wong for providing the antihuman albumin antibody.

This work was supported by grants HL-42993 and HL-02942 from the National Institutes of Health, Bethesda, MD.

\section{References}

1. Faggiotto, A. R., R. Ross, and L. Harker. 1984. Studies of hypercholesterolemia in the nonhuman primate. I. Changes that lead to fatty streak formation. Arteriosclerosis. 4:323-340.

2. Fowler, S., H. Shio, and N. H. Haley. 1979. Characterization of lipid-laden aortic cells from cholesterol-fed rabbits. IV. Investigation of macrophage-like properties of aortic cell populations. Lab. Invest. 41:372-378.

3. Gerrity, R. G. 1981. The role of the monocyte in atherogenesis. I. Transition of blood-borne monocytes into foam cells in fatty lesions. Am. J. Pathol. 103:181-190.

4. Aqel, N. M. R., R. Y. Ball, H. Waldman, and M. J. Mitchinson. 1984. Monocytic origin of foam cells in human atherosclerotic plaques. Atherosclerosis. 53:265-271.

5. Gown, A. M., T. Tsukada, and R. Ross. 1986. Human atherosclerosis. II. Immunocytochemical analysis of the cellular composition of human atherosclerotic lesions. Am. J. Pathol. 125:191-207.

6. Goldstein, J. L., Y. K. Ho, S. K. Basu, and M. S. Brown. 1979. Binding site on macrophages that mediates uptake and degradation of acetylated low density lipoprotein, producing massive cholesterol deposition. Proc. Natl. Acad. Sci. USA. 76:333-337.

7. Fogelman, A. M., I. Shechter, J. Seager, M. Hokom, J. S. Child, and P. A. Edwards. 1980. Malondialdehyde alteration of low density lipoproteins leads to cholesteryl ester accumulation in human monocyte macrophages. Proc. Natl. Acad. Sci. USA. 77:2214-2218.

8. Parthasarathy, S., D. J. Printz, D. Boyd, L. Joy, and D. Steinberg. 1986. Macrophage oxidation of low density lipoprotein generates a modified form recognized by the scavenger receptor. Arteriosclerosis. 6:505-510.

9. Clevidence, B. A., R. E. Morton, D. M. Dusek, and H. F. Hoff. 1984. 
Cholesterol esterification in macrophages. Stimulation by lipoproteins containing apo B isolated from human aortas. Arteriosclerosis. 4:196-207.

10. Khoo, J. C., E. Miller, P. McLaughlin, and D. Steinberg. 1988. Enhanced macrophage uptake of low density lipoprotein after self aggregation. Arteriosclerosis. 8:348-358.

11. Vijayagopal, P., S. R. Srinivasan, K. M. Jones, B. Radhakrishnamurthy, and G. S. Berenson. 1985. Complexes of low density lipoproteins and arterial proteoglycan aggregates promote cholesteryl ester accumulation in mouse macrophages. Biochim. Biophys. Acta. 837:251-261.

12. Salisbury, B. G. J., D. J. Falcone, and C. R. Minick. 1985. Insoluble low density lipoprotein-proteoglycan complexes enhance cholesteryl ester accumulation in macrophages. Am. J. Pathol. 120:6-11.

13. Yla-Herttula, S., O. Jaakola, T. Solakivi, H. Kuivaniemi, and T. Nikkari. 1986. The effect of proteoglycans, collagen and lysyl oxidase on the metabolism of low density lipoprotein by macrophages. Atherosclerosis. 62:73-80.

14. Hurt, E., and G. Camejo. 1987. Effect of arterial proteoglycans on the interaction of LDL and human monocyte-derived macrophages. Atherosclerosis. 67:115-126.

15. Srinivasan, S. R., P. Dolan, B. Radhakrishnamurthy, P. S. Pargaonkar, and G. S. Berenson. 1975. Lipoprotein-acid mucopolysaccharide complexes of human atherosclerotic lesions. Biochim. Biophys. Acta. 388:58-70.

16. Mawhinney, T. P., J. M. Augustyn, and K. E. Fritz. 1978. Glycosaminoglycan-lipoprotein complexes from aortas of hypercholesterolemic rabbits. I. Isolation and characterization. Atherosclerosis. 31:155-167.

17. Vijayagopal, P., S. R. Srinivasan, B. Radhakrishnamurthy, and G. S. Berenson. 1992. Lipoprotein-proteoglycan complexes from atherosclerotic lesions promote cholesteryl ester accumulation in human monocytes/macrophages. Arteriosclerosis Thromb. 12:237-249.

18. Pitas, R. E., T. L. Innerarity, and R. W. Mahley. 1983. Foam cells in explants of atherosclerotic rabbit aortas have receptors for beta-very low density lipoproteins and modified low density lipoproteins. Arteriosclerosis. 3:2-12.

19. Jaakkola, O., S. Yla-Herttuala, and T. Nikkari. 1989. Macrophage foam cells from human aortic fatty streaks take up $\beta$-VLDL and acetylated LDL in primary culture. Atherosclerosis. 79:173-182.

20. Rosenfeld, M. E., J. C. Khoo, E. Miller, S. Parthasarathy, W. Palinski, and J. L. Witztum. 1991. Macrophage-derived foam cells freshly isolated from rabbit atherosclerotic lesions degrade modified lipoproteins, promote oxidation of low density lipoproteins, and contain oxidation specific lipid-protein adducts. J. Clin. Invest. 87:90-99.

21. Hatch, F. T., and R. S. Lees. 1986. Practical method for plasma lipoprotein analysis. Adv. Lipid Res. 6:2-63.

22. Fraenkel-Conrat, H. 1957. Methods for investigating the essential groups for enzyme activity. Methods Enzymol. 4:247-269.

23. Weisgraber, K. H., T. L. Innerarity, and R. W. Mahley. 1978. Role of lysine residues of plasma lipoproteins in high affinity binding to cell surface receptors on human fibroblasts. J. Biol. Chem. 253:9053-9062.

24. McFarlane, A. M. 1958. Efficient trace labeling of proteins with iodine. Nature (Lond.). 182:53.

25. Vijayagopal, P., S. R. Srinivasan, B. Radhakrishnamurthy, and G. S. Berenson. 1981. Interaction of serum lipoproteins and a proteoglycan from bovine aorta. J. Biol. Chem. 256:8234-8241.

26. Haley, N. J., S. Shio, and S. Fowler. 1977. Characterization of lipid-laden aortic cells from cholesterol-fed rabbits. I. Resolution of aortic cell populations by metrizamide density gradient centrifugation. Lab. Invest. 37:287-296.

27. Bjornheden, T., and G. Bondjers. 1987. Oxygen consumption in aortic tissue of rabbits with diet-induced atherosclerosis. Arteriosclerosis. 7:238-247.
28. Tsukada, T., M. E. Rosenfeld, R. Ross, and A. M. Gown. 1986. Immunocytochemical analysis of cellular components in atherosclerotic lesions: use of monoclonal antibodies with Watanabe and fat-fed rabbits. Arteriosclerosis. 6:601-613.

29. Bowman, R., and R. Wolf. 1962. A rapid and specific ultramicro method for total serum cholesterol. Clin. Chem. 8:302-309.

30. Blumenkratz, N., and G. Asboe-Hansen. 1973. New method for quantitative determination of uronic acids. Anal. Biochem. 54:484-489.

31. Hartree, E. F. 1972. Determination of protein: A modification of the Lowry method that gives a linear photometric response. Anal. Biochem. 48:422427.

32. Goldstein, J. L., H. F. Hoff, Y. K. Ho, S. K. Basu, and M. S. Brown. 1981 Stimulation of cholesteryl ester synthesis in macrophages by extracts of atherosclerotic human aortas and complexes of albumin/cholesteryl esters. Arteriosclerosis. 1:210-226.

33. Morton, R. E., G. A. West, and H. F. Hoff. 1986. A low density lipoprotein-sized particle isolated from human atherosclerotic lesions is internalized by macrophages via a non-scavenger receptor mechanism. J. Lipid Res. 27:11241134.

34. Koo, C., M. E. Wernette-Hammond, Z. Garcia, M. J. Malloy, R. Uauy, C. East, D. W. Bilheimer, R. W. Mahley, and T. L. Innerarity. 1988. Uptake of cholesterol-rich remnant lipoproteins by human monocyte-derived macrophages is mediated by low density lipoprotein receptors. J. Clin. Invest. 81:1332-1340.

35. Vijayagopal, P., S. R. Srinivasan, B. Radhakrishnamurthy, and G. S. Berenson. 1991. Studies on the mechanism of uptake of low density lipoproteinproteoglycan complex in macrophages. Biochim. Biophys. Acta. 1092:291-297.

36. Vijayagopal, P., S. R. Srinivasan, B. Radhakrishnamurthy, and G. S. Berenson. 1988. Metabolism of low density lipoprotein-proteoglycan complex by macrophages: further evidence for a receptor pathway. Biochim. Biophys. Acta. 960:210-219.

37. Sparrow, C. P., S. Parthasarathy, and D. Steinberg. 1989. A macrophage receptor that recognizes oxidized low density lipoprotein but not acetylated low density lipoprotein. J. Biol. Chem. 264:2599-2604.

38. Basu, S. K., M. S. Brown, Y. K. Ho, and J. L. Goldstein. 1979. Degradation of low density lipoprotein dextran sulfate complexes associated with deposition of cholesteryl esters in mouse macrophages. J. Biol. Chem. 254:7141-7146.

39. Hurt, E., G. Bondjers, and G. Camejo. 1990. Interaction of LDL with human arterial proteoglycans stimulates its uptake by human monocyte-derived macrophages. J. Lipid Res. 31:443-454.

40. Weisgraber, K. H., T. L. Innerarity, and R. W. Mahley. 1978. Role of lysine residues of plasma lipoproteins in high affinity binding to cell surface receptors on human fibroblasts. J. Biol. Chem. 253:9053-9062.

41. Mahley, R. W., T. L. Innerarity, R. E. Pitas, K. H. Weisgraber, J. H Brown, and E. Ross. 1977. Inhibition by lipoprotein binding to cell surface receptors of fibroblasts following selective modification of arginyl residues in argininerich and $\beta$ apoproteins. J. Biol. Chem. 252:7279-7287.

42. Hoff, H. F., and B. A. Clevidence. 1987. Uptake by mouse peritoneal macrophages of large cholesteryl ester-rich perticles isolated from human atherosclerotic lesions. Exp. Mol. Pathol. 46:331-344.

43. Gudewicz, P. W., J. Molnar, M. Z. Lai, D. W. Beezhold, G. E. Siefring R. B. Credo, and L. Lorand. 1980. Fibronectin-mediated uptake of gelatin-coated latex particles by peritoneal macrophages. J. Cell Biol. 87:427-433.

44. Falcone, D. J., and B. G. J. Salisbury. 1988. Fibronectin stimulates macrophage uptake of low density lipoprotein-heparin-collagen complexes. Arteriosclerosis. 8:263-273. 